\title{
Biosorption of $\mathrm{Co}(\mathrm{II})$ by Schizosaccharomyces pombe: Kinetic and Thermodynamic Studies for Process Design
}

Nihat Alpagu Sayar, Selcen Durmaz-Sam, Gizay Odabasi and Ahmet Alp Sayar*

Department of Bioengineering, Marmara University, Kadikoy 34722, Istanbul, Turkey

\begin{abstract}
The characterisation of biosorption by Schizosaccharomyces pombe of $\mathrm{Co}(\mathrm{II})$ was done under varying experimental conditions including $\mathrm{pH}$, temperature, initial metal concentration and biosorbent dose. Optimum $\mathrm{pH}$ was found to be 5.0 with optimal biosorbent dose for highest adsorption capacity at $1.0 \mathrm{~g} \mathrm{~L}^{-1}$. Higher initial metal concentrations helped enhance $\mathrm{q}_{\mathrm{e}}$ slightly with the highest value, $2.7 \mathrm{mg} \mathrm{g}^{-1}$, being achieved at $25^{\circ} \mathrm{C}$ and $50 \mathrm{mg} \mathrm{L}^{-1}$ initial Co(II). Temkin isotherm model showed the best statistical fit for equilibrium data while Freundlich isotherm model exhibited thermodynamic consistency. Pseudo-first order kinetics was found to represent $\mathrm{Co}$ (II) biosorption. Increasing $\Delta G^{0}$ values calculated with respect to higher operational temperatures were in agreement with kinetic profiling simulations whereby higher temperatures were found to be less favourable. Overall efficiency of S. pombe as a biosorbent for $\mathrm{Co}(\mathrm{II})$ was found to be significantly less than $\mathrm{Ni}(\mathrm{II})$, for this reason it can be regarded as a potential bioseparation agent for aqueous mixtures containing both $\mathrm{Co}(\mathrm{II})$ and $\mathrm{Ni}(\mathrm{II})$.
\end{abstract}

Keywords: Biosorption; Schizosaccharomyces pombe; Adsorption isotherms; Process thermodynamics, Biokinetics; Separation

\section{Nomenclature}

$A_{0} \quad$ Frequency factor

$A_{\mathrm{T}} \quad$ Temkin isotherm equilibrium constant, $\mathrm{L} \mathrm{g}^{-1}$

$b_{\mathrm{K}} \quad$ Khan isotherm constant

$b_{\mathrm{T}} \quad$ Temkin isotherm constant

$C_{e} \quad$ Residual aqueous metal concentration at equilibrium, $\mathrm{mg} \mathrm{L}^{-1}$

$C_{\mathrm{i}} \quad$ Initial aqueous metal concentration, $\mathrm{mg} \mathrm{L}^{-1}$

$E_{\text {a }}$ Activation energy, $\mathrm{kJ} \mathrm{mol}^{-1}$

$k \quad$ Kinetic rate constant

$K_{\text {eq }} \quad$ Selected isotherm equilibrium constant

$K_{\mathrm{F}} \quad$ Freundlich isotherm equilibrium constant, $\mathrm{L} \mathrm{mg}^{-1}$

$K_{\mathrm{L}} \quad$ Langmuir isotherm equilibrium constant, $\mathrm{L} \mathrm{mg}^{-1}$

$k_{\mathrm{p} 1} \quad$ Pseudo-first order rate constant, $\mathrm{min}^{-1}$

$k_{\mathrm{p} 2} \quad$ Pseudo-second order rate constant, g mg-1 $\mathrm{min}^{-1}$

$K_{\mathrm{RP}} \quad$ Redlich-Peterson isotherm equilibrium constant, $\mathrm{L} \mathrm{g}^{-1}$

$K_{\mathrm{S}} \quad$ Sips isotherm equilibrium constant, $\left(\mathrm{mg} \mathrm{g}^{-1}\right)\left(\mathrm{mg} \mathrm{L}^{-1}\right)^{-\beta}$

$m$ Amount of biosorbent, $\mathrm{g}$

$n_{\mathrm{F}} \quad$ Freundlich isotherm exponent

$n_{\mathrm{K}} \quad$ Khan isotherm exponent

$q_{0} \quad$ Maximum metal uptake, $\mathrm{mg} \mathrm{g}^{-1}$

$q_{\mathrm{e}} \quad$ Equilibrium metal uptake, $\mathrm{mg} \mathrm{g}^{-1}$

$q_{\mathrm{i}} \quad$ Initial metal uptake rate, $\mathrm{mg} \mathrm{g}^{-1}$

$q_{\mathrm{t}} \quad$ Metal uptake at $\mathrm{t}, \mathrm{mg} \mathrm{g}^{-1}$

$R \quad$ Universal gas constant, $8.314 \mathrm{~J} \mathrm{~mol}^{-1} \mathrm{~K}^{-1}$

$R^{2} \quad$ Correlation coefficient
RMSE Root mean square error

T Time, s or hr

$T \quad$ Temperature, $\mathrm{K}$

$V \quad$ Volume of aqueous phase, $\mathrm{L}$

$\alpha_{\mathrm{RP}} \quad$ Redlich-Peterson isotherm constant

$\alpha_{\mathrm{S}} \quad$ Sips isotherm constant, $\left(\mathrm{L} \mathrm{mg}^{-1}\right)^{\beta}$

$\beta_{\mathrm{RP}} \quad$ Redlich-Peterson isotherm exponent

$\beta_{\mathrm{s}} \quad$ Sips isotherm exponent

$\Delta G^{0} \quad$ Gibbs free energy change, $\mathrm{J} \mathrm{mol}^{-1}$

$\Delta H^{0} \quad$ Enthalpy change, $\mathrm{J} \mathrm{mol}^{-1}$

$\Delta S^{0} \quad$ Entropy change, $\mathrm{J} \mathrm{mol}^{-1} \mathrm{~K}^{-1}$

\section{Introduction}

Biosorption of heavy metal ions from aqueous solutions is an area where there are growing interest and success [1]. Previous studies have shown that wild-type Schizosaccharomyces pombe is a promising agent for the biosorption of nickel(II) from aqueous solutions [2] Considering the fact that in most naturally and technologically relevant conditions cobalt(II) is found along with nickel(II), it is a logical undertaking to investigate the biosorption properties of wild-type $S$. pombe for cobalt(II) for both biohydrometallurgical separation and environmental control purposes.

*Corresponding author: Ahmet Alp Sayar, Department of Bioengineering Marmara University, Kadikoy 34722, Istanbul, Turkey, Tel: 90-216-348 0295 ext. 718; Fax: 90-216-345 01 26;Email: asayar@marmara.edu.tr

Received August 20, 2013; Accepted November 11, 2013; Published November 15, 2013

Citation: Sayar NA, Durmaz-Sam S, Odabasi G, Sayar AA (2013) Biosorption of $\mathrm{Co}$ (II) by Schizosaccharomyces pombe Kinetic and Thermodynamic Studies for Process Design J Bioprocess Biotech 3: 138 doi: 10.4172/21559821.1000138

Copyright: @ 2013 Sayar AA, et al. This is an open-access article distributed unde the terms of the Creative Commons Attribution License, which permits unrestricted use, distribution, and reproduction in any medium, provided the original author and source are credited. 
A variety of biological materials have been examined as biosorption agents for Co(II). Among these are marine algae Ascophyllum nodosum [3], crab shell particles [4], fungi of genera Aspergillus, Rhizopus [5] and Saccharomyces [1]. This study focuses on the biosorptive properties of $S$. pombe on Co(II). Advantages of using this organism are its rapid growth rate, high biomass yield and non-pathogenic character. These advantages also ensure cheaper and easier production at large scales.

It also has to be noted that there has been mounting interest in using membrane processes for the separation of cobalt and nickel in aqueous solutions. The reported separation factors achieved using some of these processes are very high, with examples like 80 [6] or 250 [7]. Although such values are seemingly remarkable, one has to keep in mind that membrane technology displays some serious disadvantages in terms of industrial application such as scale-up and staging difficulties and membrane fouling. Therefore, adsorption and solvent extraction methods for the separation of heavy metals still hold primary importance in scientific research and industrial applications.

Characterisation of biosorption properties is an essential prerequisite for further design studies towards industrial application of such processes. Characterisation of the biosorbent properties of $S$. pombe for $\mathrm{Co}$ (II) comprises the main aim of the current paper. Fundamental aspects for such a characterisation include equilibrium, kinetic and thermodynamic analyses of the biosorption process. Effects of $\mathrm{pH}$, initial aqueous metal concentration and biosorbent dose also constitute the key aspects of such a study. On top of these conventional and generally performed investigations, the scope of this study also covers the kinetic profiling of and preliminary design calculations for a single stage batch biosorber.

The biosorption of Co(II) by $S$. pombe is presumed to happen via a passive ion exchange process between the aqueous metal and the cellular surface of the biosorbent. Process parameters such as the $\mathrm{pH}$ and temperature and initial biomass and metal concentrations in the aqueous media affect the binding between the organism and the metal. Accordingly, these parameters are to be examined in order to assess the feasibility of an industrial application [8]. Industrial feasibility assessment and comparison with alternative systems also require an understanding of the performance of the system for which kinetic information and preliminary design calculations are informative [9].

The biosorption characterisation procedure follows the single sorbate-simple closed batch system methodology. The details of this approach are available in a previous study [2]. The equilibrium values of $\mathrm{Co}$ (II) uptake by the biomass, $\mathrm{q}_{\mathfrak{e}}$, $\mathrm{mg}$ (g dry weight) ${ }^{-1}$ can be calculated using:

$$
q_{\mathrm{e}}=\frac{\left(C_{\mathrm{i}}-C_{\mathrm{e}}\right) V}{m}
$$

where $C_{i}, C_{e}, V$ and $m$ denote, initial $\mathrm{Co}(\mathrm{II})$ concentration of the aqueous phase $\left(\mathrm{mg} \mathrm{L}^{-1}\right)$, equilibrium $\mathrm{Co}$ (II) concentration of the aqueous phase $\left(\mathrm{mg} \mathrm{L}^{-1}\right)$, volume $(\mathrm{L})$ of the solution contacted with sorbent and the amount of the sorbent expressed as dry mass (g), respectively.

Adsorption isotherms were used for the assessment and evaluation of biosorption of $\mathrm{Co}$ (II) onto S. pombe. These isotherms can be further employed during the preliminary equipment design for a relevant industrial process. Six different adsorption isotherm models were considered for this study. Langmuir, Freundlich, Langmuir-Freundlich (Sips) and Redlich-Peterson isotherms were chosen since they are the most studied and best understood models. Khan and Temkin isotherms [10] were also included. Khan isotherm shows characteristic similarities to the above-mentioned ones, thus offers a possibility of a good fit. Although it is argued elsewhere that Temkin isotherm might not be appropriate for complex adsorption systems including liquidphase adsorption [11]; Temkin isotherm features a linear dependency to biosorption heat which is in agreement with the observations made of the present system. Mathematical descriptions of these isotherm models can be found in Table 1. Once an isotherm is found to be satisfactorily descriptive of the studies it will be used in an elementary design of a single-stage batch biosorber.

Another important aspect of the characterisation of biosorption is an adequate description of the kinetics of the interaction between the biosorbent and the adsorbate. Pseudo-first or pseudo-second order kinetics is usually found to be adequately descriptive of the biosorption phenomenon [1]. Relevant rate equations are given in Table 2. The appropriate rate equations that describe the currently studied system will be used in a preliminary modelling scheme to simulate the kinetic biosorption profiles.

The third essential part of biosorbent characterisation is the thermodynamic analysis of the process, in terms of feasibility and energy consumption studies as a precedent for industrial design approaches. Thermodynamic functions such as activation energy, Gibbs free energy change, enthalpy and entropy changes are crucial for process design calculations. The activation energy, $E_{\mathrm{a}}$ in $\mathrm{kJ} \mathrm{mol}^{-1}$, can be calculated using:

$$
\ln k=\frac{-E_{\mathrm{a}}}{R T}+\ln A_{0}
$$

The calculated value for $E_{\mathrm{a}}$ is an index to be used to distinguish if the biosorption in question is either of a physical or a chemical nature. $\Delta G^{0}$ can be calculated by:

$$
\Delta G^{0}=-R T \ln K_{\text {eq }}
$$

\begin{tabular}{|c|c|}
\hline Biosorption isotherm & Formulae \\
\hline Langmuir & $q_{\mathrm{e}}=\frac{q_{0} K_{\mathrm{L}} C_{\mathrm{e}}}{1+K_{\mathrm{L}} C_{\mathrm{e}}}$ \\
\hline Freundlich & $q_{\mathrm{e}}=K_{\mathrm{F}} C_{\mathrm{e}}^{1 / n_{\mathrm{F}}}$ \\
\hline Langmuir-Freundlich (Sips) & $q_{\mathrm{e}}=\frac{K_{\mathrm{S}} C_{\mathrm{e}}^{\beta_{\mathrm{S}}}}{1+\alpha_{\mathrm{S}} C_{\mathrm{e}}^{\beta_{\mathrm{s}}}}$ \\
\hline Redlich-Peterson & $q_{\mathrm{e}}=\frac{K_{\mathrm{RP}} C_{\mathrm{e}}}{1+\alpha_{\mathrm{RP}} C_{\mathrm{e}}^{\beta_{\mathrm{RP}}}} c$ \\
\hline Khan & $q_{\mathrm{e}}=\frac{q_{0} b_{\mathrm{K}} C_{\mathrm{e}}}{\left(1+b_{\mathrm{K}} C_{\mathrm{e}}\right)^{n_{\mathrm{K}}}}$ \\
\hline Temkin & $q_{\mathrm{e}}=\frac{R T}{b_{\mathrm{T}}} \ln \left(A_{\mathrm{T}} C_{\mathrm{e}}\right)$ \\
\hline
\end{tabular}

Table 1: Isotherm models applied to the biosorption data

\begin{tabular}{|c|l|c|}
\hline Kinetic model & Differential form & Integrated form \\
\hline Pseudo-first order & $\frac{d q}{d t}=k_{p 1}\left(q_{e}-q_{t}\right)$ & $\log \left(q_{e}-q_{t}\right)=\log q_{e}-\frac{-k_{p 1}}{2.303} t$ \\
\hline Pseudo-second order & $\frac{d q}{d t}=k_{p 2}\left(q_{e}-q_{t}\right)^{2}$ & $q_{t}=\frac{t}{\frac{1}{k_{p 2} q_{e}^{2}}+\frac{t}{q_{e}}}$ \\
\hline
\end{tabular}

Table 2: Kinetic models applied to the biosorption data. 
where $R$ is the gas constant $\left(8.314 \mathrm{~J} \mathrm{~mol}^{-1} \mathrm{~K}^{-1}\right)$, $\mathrm{T}$ is the temperature in Kelvin; $K_{\mathrm{eq}}$ (selected equilibrium constant) used in $\mathrm{L} \mathrm{mol}{ }^{-1}$. By employing the selected equilibrium constant, the following linear thermodynamic relation can be obtained:

$$
\ln K_{\mathrm{eq}}=\frac{-\Delta H^{0}}{R T}+\frac{\Delta S^{0}}{R}
$$

\section{Materials and Methods}

\section{Preparation of the biosorbent}

The wild-type strain of $S$. pombe ( $972 h$ ) obtained from University of Istanbul, Deparment of Molecular Biology and Genetics, Turkey, was first cultivated, then harvested and finally prepared to be used as biosorbent in this study. For the cultivation of yeast cells, cultures on agar slants were used to inoculate $100 \mathrm{ml}$ of sterile preculturing medium consisting of $30 \mathrm{~g} \mathrm{~L}^{-1}$ glucose and $5 \mathrm{~g} \mathrm{~L}^{-1}$ yeast extract. Preculturing medium was incubated at $30^{\circ} \mathrm{C}$ by shaking at a rate of $180 \mathrm{rpm}$ until the early stationary growth phase which was determined by the intermittent spectrophotometric measurements of cell culture's optical density at $600 \mathrm{~nm}$. Then, $200 \mathrm{ml}$ of sterile media containing 30 $\mathrm{g} \mathrm{L}^{-1}$ glucose and $5 \mathrm{~g} \mathrm{~L}^{-1}$ yeast extract in $500 \mathrm{ml}$ Erlenmeyer flasks were inoculated with previously prepared preculture at an inoculum ratio of $1 / 100(\mathrm{v} / \mathrm{v})$. The flasks were agitated at $180 \mathrm{rpm}$ at $30^{\circ} \mathrm{C}$ for $40 \mathrm{~h}$ when the optical density of cultures at $600 \mathrm{~nm}$ showed negligible changes. The yeast cells were separated from the media by centrifugation at 9,000 rpm for $3 \mathrm{~min}$ at $20^{\circ} \mathrm{C}$. Liquid part was discarded and cell pellet was washed twice with ultra-pure grade water. In order to dry yeast cells the pellet was kept at $50^{\circ} \mathrm{C}$ for $72 \mathrm{~h}$. Dried cell chunks were grinded with the help of a blender. Dry biomass was preserved in a desiccator until it was used in biosorption experiments.

Sterilization of all growth media and flasks was accomplished in an autoclave (OT 032 Nüve, Turkey) at $121^{\circ} \mathrm{C}$ and 1.0 atm for $15 \mathrm{~min}$. $\mathrm{Co}(\mathrm{II})$ stock solution with a concentration of $1 \mathrm{~g} \mathrm{~L}^{-1}$ was prepared by dissolving a proper amount of $\mathrm{CoCl}_{2} \cdot 6 \mathrm{H}_{2} \mathrm{O}$ (Analytical Grade, Carlo Erba, France) in ultra-pure water.

\section{Biosorption experiments}

In order to determine the optimum $\mathrm{pH}$ for the current biosorption system, experiments were conducted at varying $\mathrm{pH}$ values. Five Erlenmeyer flasks $(250 \mathrm{~mL})$, each containing $100 \mathrm{~mL}$ of $10 \mathrm{mg} \mathrm{L}^{-1}$ $\mathrm{Co}(\mathrm{II})$ solution, were prepared and adjusted to $\mathrm{pH} 2.0,3.0,4.0,5.0$ and $6.0( \pm 0.1)$ respectively, by the addition of either 0.1 (or 1.0) $\mathrm{N} \mathrm{HNO}_{3}$ or 0.1 (or 1.0) $\mathrm{N} \mathrm{NaOH}$. Dry biomass of $S$. pombe cells was added to each flask to obtain a concentration of $1 \mathrm{~g} \mathrm{~L}^{-1}$. The flasks were shaken for duration of $2 \mathrm{~h}$ at $150 \mathrm{rpm}$ and $25^{\circ} \mathrm{C}$. $\mathrm{pH} 5.0 \pm 0.1$ was found to be the optimal operating value used throughout the rest of the experiments.

Further experimentation was conducted using the abovementioned setup but with different initial metal concentration values $(2.7 \pm 0.1$, $5.2 \pm 0.2,7.3 \pm 0.2,11.1 \pm 1.1$, and $\left.53.8 \pm 2.8 \mathrm{mg} \mathrm{L}^{-1}\right)$ and at various operational temperatures $\left(25,30,35\right.$ and $\left.50 \pm 0.2^{\circ} \mathrm{C}\right)$. Samples were taken at predetermined time intervals and centrifuged for $5 \mathrm{~min}$ at $10,000 \mathrm{rpm}$ and $20^{\circ} \mathrm{C}$. Initial and residual $\mathrm{Co}(\mathrm{II})$ concentrations of the samples were measured using a Thermo Scientific Atomic Absorption Spectrophotometer (Model: iCE 3500) at $240.7 \mathrm{~nm}$. All experiments were conducted in triplicate.

\section{Results and Discussion}

\section{Effect of $\mathbf{p H}$}

The $\mathrm{pH}$ of the solution within which biosorption takes place influences both the metal and cell surface chemistry and thus is an important operational parameter for a biosorption process. Determination of the optimum $\mathrm{pH}$ value for the current $\mathrm{Co}$ (II) biosorption system was done by experımentation at $25^{\circ} \mathrm{C}$ whereby $10 \mathrm{mg} \mathrm{L}^{-1} \mathrm{Co}(\mathrm{II})$ solutions with a biomass concentration of $1 \mathrm{~g} \mathrm{~L}^{-1}$ each and $\mathrm{pH}$ values ranging from 2.0 to 6.0 (by increments of 1.0) were used. $\mathrm{pH}$ values over 6.0 weren't considered due to the fact that no improvement on metal uptake was observed over $\mathrm{pH}$ 5.0. Figure 1 displays that optimum $\mathrm{Co}(\mathrm{II})$ uptake is attained at $\mathrm{pH} 5.0$ where $\mathrm{q}_{\mathrm{e}}$ equals $2.55 \mathrm{mg} \mathrm{g}^{-1}$. Almost a linearly correlated increase in metal uptake accompanies the increasing $\mathrm{pH}$ of the medium from $\mathrm{pH} 2.0$ to 5.0 where a peak is reached and a slow decline can be observed afterwards. An impressive ten-fold increase in metal uptake is achieved when working at $\mathrm{pH} 5.0$ compared to $\mathrm{pH}$ 2.0. An increase in the $\mathrm{pH}$ might affect the ionic configuration of some of the functional groups esp. at the cellular surface and improve the interactions with the metal ions.

\section{Effect of sorbent dose}

Four experiments with different biosorbent concentrations were conducted to observe the effect of sorbent dose on metal uptake. $50 \mathrm{mg} \mathrm{L}^{-1} \mathrm{Co}$ (II) solutions with $0.5,1.0,2.0$ and $3.0 \mathrm{~g} \mathrm{~L}^{-1} \mathrm{~S}$. pombe concentrations were used at $25^{\circ} \mathrm{C}$ and $\mathrm{pH}$ 5. Although the total amount of metal adsorbed increased with higher biosorbent concentrations (from $1.1 \mathrm{mg} \mathrm{L}^{-1}$ at the lowest biosorbent concentration to $6.2 \mathrm{mg} \mathrm{L}^{-1}$ at the highest); the adsorption capacity peaked at $1.0 \mathrm{~g} \mathrm{~L}^{-1}$ biosorbent concentration with a value of $2.7 \mathrm{mg} \mathrm{g}^{-1}$. Figure 2 exhibits the trend with which metal uptake at equilibrium relates to biosorbent concentration. The reason why equilibrium metal uptake falls with very high biosorbent concentrations, contrary to expectation, may be due to increased electrostatic interactions between the cells which obstruct the contact between metal cations and cellular binding sites; since it cannot be due to the insufficiency of solute to cover all available binding sites considering the significant amounts of residual metal in solution at equilibrium, observed even at optimal uptake conditions. Over $50 \%$ of metal remains in solution under all conditions tested.

A techno-economic trade-off between the cost of biosorbent and the amount of metal adsorbed per unit of the biosorbent exists which a thorough cost-benefit analysis of these parameters may resolve but it

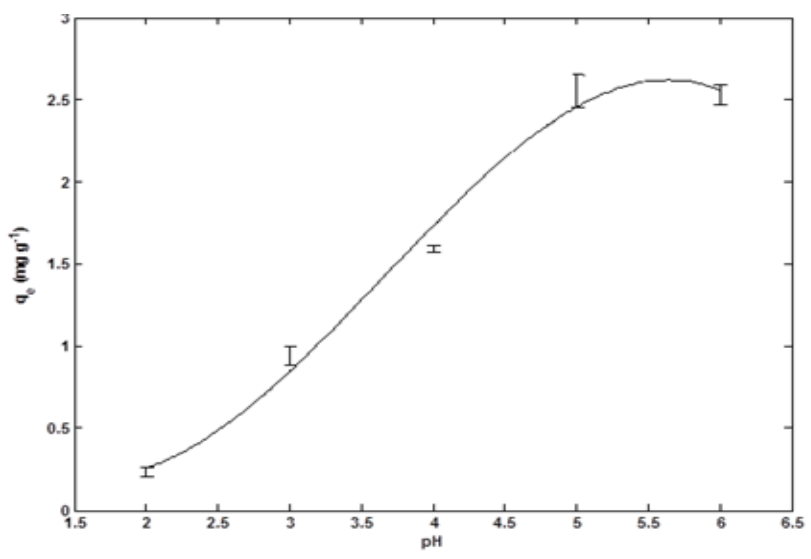

Figure 1: Effect of $\mathrm{pH}$ on the equilibrium uptake of $\mathrm{Co}$ (II) by $S$ pombe (Temperature: $25^{\circ} \mathrm{C}$, initial $\mathrm{Co}(\mathrm{II})$ conc.: $10 \mathrm{mg} \mathrm{L}^{-1}$, biosorbent dose: $1.0 \mathrm{~g} \mathrm{~L}^{-1}$, agitation rate: $150 \mathrm{rpm}$. The bars represent standard deviation of the mean). 
Citation: Sayar NA, Durmaz-Sam S, Odabasi G, Sayar AA (2013) Biosorption of Co(II) by Schizosaccharomyces pombe: Kinetic and Thermodynamic Studies for Process Design. J Bioprocess Biotech 3: 138 doi: 10.4172/2155-9821.1000138

Page 4 of 8

falls out of the scope of this study.

\section{Equilibrium studies}

Isotherm models: Elucidation of an appropriate biosorption equilibrium correlation is an essential component for reliable prediction of biosorption parameters and quantitative comparison and effective design of different biosorption systems [11]. Experimental equilibrium data of the $\mathrm{Co}$ (II) biosorption system was analysed using established isotherm models Langmuir, Freundlich, combined LangmuirFreundlich (Sips), Redlich-Peterson, Khan and Temkin isotherms. Langmuir, Freundlich and Temkin are two-parameter models whereas the others have three parameters. The three-parameter Sips, RedlichPeterson and Khan isotherms are modified versions of the Langmuir isotherm combining its features with that of Freundlich. Temkin isotherm is a two-parameter model including a term for temperature.

The correlation between the observed variables $C_{e}$ and $q_{e}$ has been analysed using Matlab R2012b's NonLinearModel fit function to determine the optimised values of the model parameters. The use of adjusted-R2 (square of the correlation factor) as statistical performance index is necessitated by the multivariate and nonlinear characteristics of the isotherm model equations. Additionally, root mean square error (RMSE) values for each fitted model are produced as a way to aid the statistical assessment. The results are tabulated in Table 3.

Across all experimentally observed conditions Temkin isotherm model exhibits the best fit statistically.

Effect of initial metal concentration on equilibrium metal uptake: Biosorption processes with varying initial metal concentrations between 2.5 and $50 \mathrm{mg} \mathrm{L}^{-1}$ were tested at four different operating temperatures. The experimental results are compared with Temkin isotherm models optimised with appropriate data in Figure 3. The plots show the effect of initial metal concentration, $C_{i}$, on the isothermal relationship between equilibrium values of $C_{e}$ and $q_{e}$. An increase of initial metal concentration from 2.5 to $50 \mathrm{mg} \mathrm{L}^{-1}$ shows a positive effect, albeit very minor for initial metal concentrations above $10 \mathrm{mg} \mathrm{L}^{-1}$, on the equilibrium values for all temperatures tested. It can be said that, above that level, either saturation of the binding sites on cell surfaces occurs or adsorptive (e.g. affinity between metal ions and cell surface) and desorptive (e.g. electrostatic repulsion between metal ions) forces balance. It has also to be noted that at these metal concentrations and $\mathrm{pH}$ value (5.0) precipitation of metal ions doesn't take place.

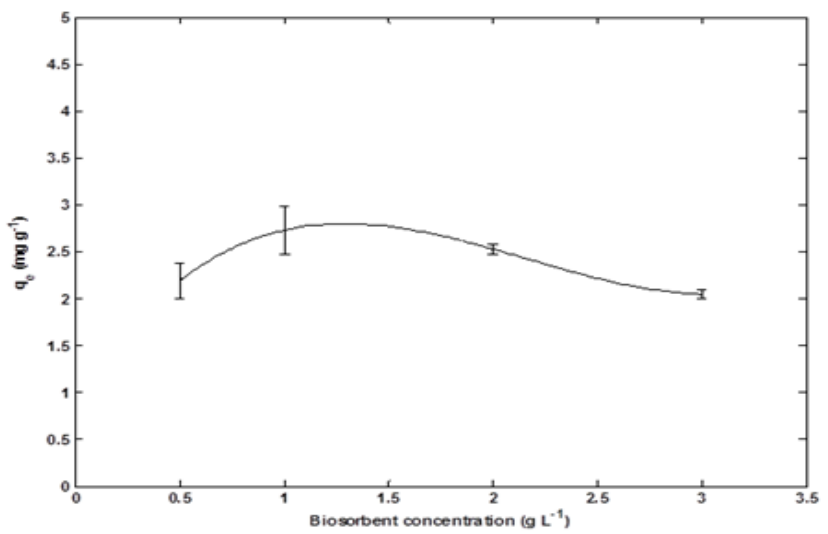

Figure 2: Effect of sorbent dose on equilibrium uptake of Co(II) by S. pombe (Temperature: $25^{\circ} \mathrm{C}$, initial Co(II) conc.: $50 \mathrm{mg} \mathrm{L}-1$, biosorbent dose: $1.0 \mathrm{~g} \mathrm{~L}^{-1}$, agitation rate: $150 \mathrm{rpm}$. The bars represent standard deviation of the mean).
Combined effect of temperature and initial metal concentration: Figure 4 displays the combined effect of two independent process parameters, namely temperature and initial $\mathrm{Co}(\mathrm{II})$ concentration in solution on equilibrium metal uptake. Lower temperatures and higher initial concentrations seem to be favoured by the biosorption process. The kind of information inferred from such plots is valuable for guiding the overall design of the whole industrial application. It can be said that one would favour operations upstream of the biosorption process to carry lower temperature outputs and that there would be a trade-off between maintaining lower upstream temperatures and cooling efforts that might be required to increase the efficiency of the biosorption process. Quantified representation of such information aids the preliminary design calculations for the whole process and guides early design decisions.

\begin{tabular}{|c|c|c|c|c|c|}
\hline Adsorption model & $\mathbf{T}\left({ }^{\circ} \mathbf{C}\right)$ & $\mathbf{K}_{\mathbf{L}}$ & $\mathbf{q}_{\mathbf{0}}$ & Adj-R $^{2}$ & RMSE \\
\hline \multirow{3}{*}{ Langmuir } & 25 & 0.526 & 2.690 & 0.725 & 0.286 \\
\cline { 2 - 6 } & 30 & 0.717 & 2.184 & 0.751 & 0.198 \\
\cline { 2 - 6 } & 35 & 0.924 & 1.796 & 0.830 & 0.114 \\
\cline { 2 - 6 } & 50 & 1.497 & 1.548 & 0.931 & 0.046 \\
\hline
\end{tabular}

\begin{tabular}{|c|c|c|c|c|c|}
\hline Adsorption model & $\mathbf{T}\left({ }^{\circ} \mathbf{C}\right)$ & $\mathbf{K}_{\mathbf{F}}$ & $\mathbf{n}_{\mathbf{F}}$ & Adj-R & RMSE \\
\hline \multirow{3}{*}{ Freundlich } & 25 & 1.346 & 5.387 & 0.871 & 0.196 \\
\cline { 2 - 6 } & 30 & 1.234 & 6.328 & 0.849 & 0.154 \\
\cline { 2 - 6 } & 35 & 1.121 & 7.615 & 0.975 & 0.044 \\
\cline { 2 - 6 } & 50 & 1.128 & 11.063 & 0.888 & 0.058 \\
\hline
\end{tabular}

\begin{tabular}{|c|c|c|c|c|c|c|}
\hline $\begin{array}{c}\text { Adsorption } \\
\text { model }\end{array}$ & $\mathbf{T}\left({ }^{\circ} \mathbf{C}\right)$ & $\mathbf{K}_{\mathbf{s}}$ & $\mathbf{a}_{\mathbf{s}}$ & $\boldsymbol{\beta}_{\mathbf{s}}$ & Adj-R & RMSE \\
\hline \multirow{3}{*}{ Sips } & 25 & 1.752 & 0.406 & 0.376 & 0.827 & 0.227 \\
\cline { 2 - 7 } & 30 & 1.829 & 0.634 & 0.441 & 0.820 & 0.169 \\
\hline & 35 & 1.804 & 0.721 & 0.355 & 0.992 & 0.024 \\
\hline & 50 & 2.550 & 1.522 & 0.589 & 0.975 & 0.028 \\
\hline
\end{tabular}

\begin{tabular}{|c|c|c|c|c|c|c|}
\hline $\begin{array}{c}\text { Adsorption } \\
\text { model }\end{array}$ & $\mathbf{T}\left({ }^{\circ} \mathbf{C}\right)$ & $\mathbf{K}_{\mathrm{RP}}$ & $\boldsymbol{\alpha}_{\mathrm{RP}}$ & $\boldsymbol{\beta}_{\mathrm{RP}}$ & $\mathbf{A d j} \mathbf{R}^{2}$ & $\mathbf{R M S E}$ \\
\hline $\begin{array}{c}\text { Redlich- } \\
\text { Peterson }\end{array}$ & 25 & 9.713 & 6.637 & 0.836 & 0.813 & 0.236 \\
\cline { 2 - 7 } & 30 & 5.001 & 3.480 & 0.882 & 0.803 & 0.176 \\
\cline { 2 - 7 } & 35 & 5.689 & 4.525 & 0.898 & 0.992 & 0.025 \\
\cline { 2 - 7 } & 50 & 3.749 & 2.783 & 0.958 & 0.981 & 0.024 \\
\hline
\end{tabular}

\begin{tabular}{|c|c|c|c|c|c|c|}
\hline $\begin{array}{c}\text { Adsorption } \\
\text { model }\end{array}$ & $\mathbf{T}\left({ }^{\circ} \mathbf{C}\right)$ & $\mathbf{b}_{\mathbf{k}}$ & $\mathbf{q}_{\mathbf{0}}$ & $\mathbf{n}_{\mathbf{k}}$ & Adj-R $^{\mathbf{2}}$ & RMSE \\
\hline \multirow{3}{*}{ Khan } & 25 & 7.343 & 1.013 & 0.829 & 0.811 & 0.237 \\
\cline { 2 - 7 } & 30 & 3.411 & 1.201 & 0.876 & 0.801 & 0.177 \\
\cline { 2 - 7 } & 35 & 4.284 & 1.064 & 0.895 & 0.992 & 0.025 \\
\cline { 2 - 7 } & 50 & 2.717 & 1.277 & 0.956 & 0.982 & 0.023 \\
\hline
\end{tabular}

\begin{tabular}{|c|c|c|c|c|c|}
\hline Adsorption model & $\mathbf{T}\left({ }^{\circ} \mathbf{C}\right)$ & $\mathbf{A}_{\mathbf{T}}$ & $\mathbf{b}_{\mathbf{T}}$ & $\mathbf{A d j - R}^{\mathbf{2}}$ & $\mathbf{R M S E}$ \\
\hline \multirow{2}{*}{ Temkin } & 25 & 23.567 & 6386.6 & 0.878 & 0.191 \\
\cline { 2 - 6 } & 30 & 56.442 & 8814.2 & 0.872 & 0.142 \\
\cline { 2 - 6 } & 35 & 186.64 & 12536.0 & 0.992 & 0.024 \\
\cline { 2 - 6 } & 50 & 5066.8 & 20808.0 & 0.920 & 0.049 \\
\hline
\end{tabular}

Table 3: Parameters and statistics of the fitted isotherm models. 

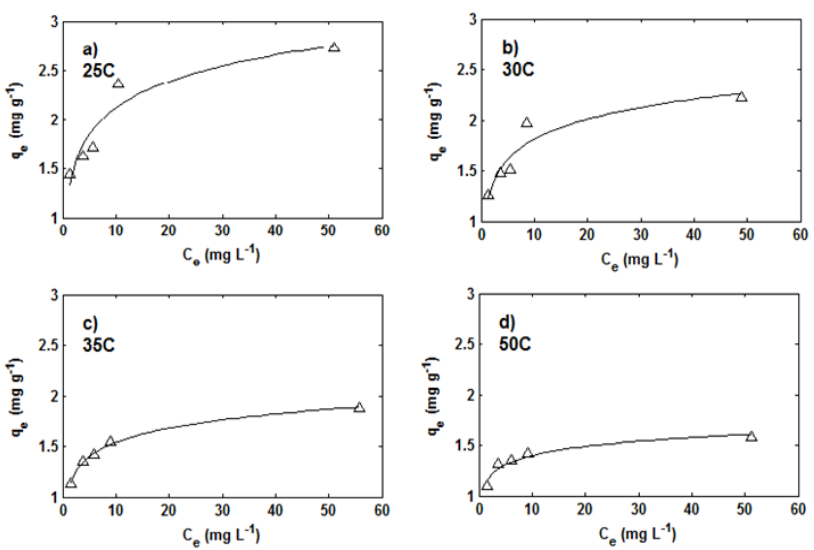

Figure 3: Effect of initial $\mathrm{Co}(\mathrm{II})$ concentration on the isothermal relationship between metal uptake and residual metal concentration at equilibrium with fitted Temkin isotherms ( $\mathrm{pH}$ 5.0, biosorbent dose: $1.0 \mathrm{~g} \mathrm{~L}^{-1}$, agitation rate: $150 \mathrm{rpm}$ ).

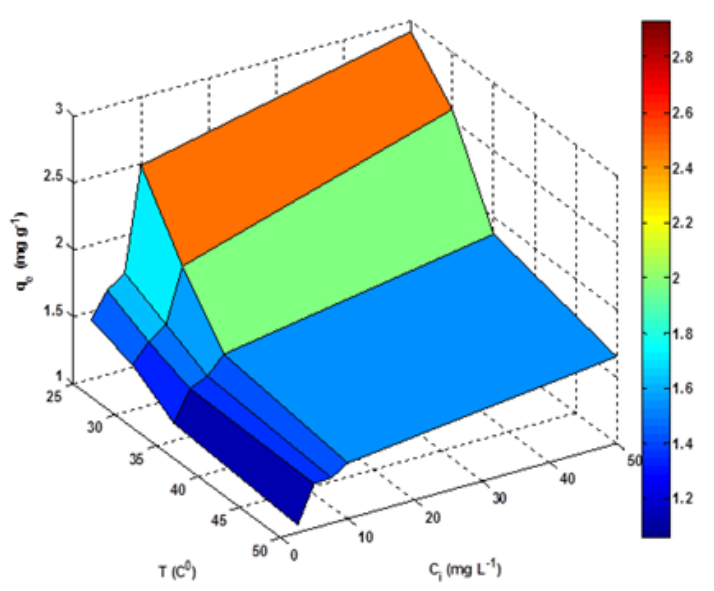

Figure 4: Combined effect of temperature and initial Co(II) concentration on biosorption by inactive $S$. pombe.

\section{Biosorption kinetics}

Determining the kinetics of a biosorption process is a key step towards reactor sizing and process optimisation. The rate of adsorption can be calculated by considering the biosorption process as a reaction system and assuming biosorbent concentration to be in great excess with respect to sorbent concentration. Following these assumptions biosorbate concentration can be grouped with the basic rate constant yielding a pseudo-constant which can be used in either a first or second order kinetic model. Both the pseudo-first and pseudo-second order approaches have been tested to correlate the present experimental data. Calculations were done using initial metal concentration values of 2.5, 5.0, 7.5, 10.0 and $50.0 \mathrm{mg} \mathrm{L}^{-1}$ at $25,30,35$ and $50^{\circ} \mathrm{C}$ temperatures. It was found that pseudo-first order kinetics showed a better fit statistically. Optimised pseudo-first order rate constants with observed and calculated values for equilibrium metal uptake are reported in Table 4 along with statistical parameters.

Statistical analysis of the fit of kinetic data to pseudo-first and pseudo-second order models reveals marginally Better Square of correlation factors, $R^{2}$, for the former. A better fitting pseudo-first order kinetics might imply the absence of a chemical sorption mechanism between $\mathrm{Co}$ (II) and the cellular surface of $S$. pombe or its insignificance in comparison to physical interactions. It is also clear from equilibrium metal uptake values that the overall biosorption of $\mathrm{Co}(\mathrm{II})$ by $S$. pombe is not a very efficient process. These observations should be considered in an industrial application context, in terms of the reversibility of this operation and its potential use in a multi-component biosorption process.

\section{Preliminary design calculations for a single stage biosorber}

An important step towards the industrial design of a biosorption process is the utilisation of the characterisation data (biosorption isotherms) for the calculation of some relevant metrics [12]. The operating volume of a single stage operation is an important metric in terms of equipment design and operational costs. Determination of the biosorbent mass required achieving a target percentage removal for a given operating volume at a given $\mathrm{pH}$ and temperature is a design objective. The mass balance for $\mathrm{Co}$ (II) over a single stage of biosorption, depicted in Figure 5, at equilibrium is as follows:

$$
V\left(C_{\mathrm{i}}+[\text { Spombe }]_{\mathrm{i}} q_{\mathrm{i}}\right)=V\left(C_{\mathrm{e}}+[\text { Spombe }]_{\mathrm{e}} q_{\mathrm{e}}\right)
$$

Assuming biosorbent amount doesn't change (i.e. $[\text { Spombe }]_{\mathrm{i}}=[\text { Spombe }]_{\mathrm{e}}$ ) throughout the process and substituting in the Temkin isotherm, the above equation yields: at equilibrium.

$$
[\text { Spombe }]_{\mathrm{i}}=\frac{C_{\mathrm{i}}-C_{\mathrm{e}}}{\frac{R T}{b_{\mathrm{T}}} \ln A_{\mathrm{T}} C_{\mathrm{e}}}
$$

Figure 6 displays the amount of biosorbent needed to achieve predetermined percentage removal of metal in terms of varying operational volume. Although optimal biosorbent dose has been found to be $1.0 \mathrm{~g} \mathrm{~L}^{-1}$, this optimality is in terms of the adsorption capacity of the biosorbent. If the cost of biosorbent is a critical factor for process design then this optimality is an important measure. However, if there is a trade-off between the cost of biosorbent and the cost of downstream operations then the kind of information gained from Figure 6 becomes

\begin{tabular}{|c|c|c|c|c|c|}
\hline \multirow[t]{2}{*}{$T\left({ }^{\circ} \mathrm{C}\right)$} & \multirow[t]{2}{*}{$C_{\mathrm{i}}\left(\mathrm{mg} \mathrm{L}^{-1}\right)$} & \multirow[t]{2}{*}{$q_{\text {e-exp }}\left(m g^{-1}\right)$} & \multicolumn{3}{|c|}{ Pseudo-first order model } \\
\hline & & & $k_{\mathrm{p} 1}$ & $q_{\mathrm{e}-\mathrm{cal}}\left(\mathrm{mg} \mathrm{g}^{-1}\right)$ & $R^{2}$ \\
\hline \multirow[t]{5}{*}{25} & 2.790 & 1.437 & 2.501 & 1.413 & 0.9998 \\
\hline & 5.511 & 1.630 & 2.167 & 1.633 & 0.9999 \\
\hline & 7.440 & 1.724 & 1.712 & 1.725 & 0.9983 \\
\hline & 12.813 & 2.367 & 0.563 & 2.542 & 0.9996 \\
\hline & 53.716 & 2.728 & 0.187 & 2.997 & 0.9988 \\
\hline \multirow[t]{5}{*}{30} & 2.594 & 1.255 & 2.359 & 1.337 & 0.9999 \\
\hline & 5.182 & 1.473 & 1.863 & 1.492 & 0.9998 \\
\hline & 7.039 & 1.515 & 1.491 & 1.562 & 0.9933 \\
\hline & 10.553 & 1.967 & 0.397 & 1.934 & 0.9925 \\
\hline & 51.068 & 2.226 & 0.110 & 2.589 & 0.9942 \\
\hline \multirow[t]{5}{*}{35} & 2.603 & 1.131 & 1.891 & 1.141 & 0.9986 \\
\hline & 5.088 & 1.355 & 1.557 & 1.361 & 0.9979 \\
\hline & 7.407 & 1.416 & 1.219 & 1.381 & 0.9974 \\
\hline & 10.528 & 1.544 & 0.283 & 1.564 & 0.9989 \\
\hline & 57.600 & 1.878 & 0.046 & 1.852 & 0.9997 \\
\hline \multirow[t]{5}{*}{50} & 2.630 & 1.100 & 1.765 & 1.066 & 0.9988 \\
\hline & 5.011 & 1.316 & 1.396 & 1.335 & 0.9934 \\
\hline & 7.448 & 1.346 & 0.618 & 1.358 & 0.9968 \\
\hline & 10.630 & 1.416 & 0.183 & 1.419 & 0.9975 \\
\hline & 52.787 & 1.578 & 0.023 & 1.656 & 0.9981 \\
\hline
\end{tabular}
important in guiding process design decisions.

Table 4: Pseudo-first order kinetic model. 
Citation: Sayar NA, Durmaz-Sam S, Odabasi G, Sayar AA (2013) Biosorption of Co(II) by Schizosaccharomyces pombe: Kinetic and Thermodynamic Studies for Process Design. J Bioprocess Biotech 3: 138 doi: 10.4172/2155-9821.1000138

Page 6 of 8

\section{Determination of thermodynamic properties}

The pseudo-first order kinetic equilibrium constant can be utilised to calculate the activation energies for the predetermined experimental conditions using equation 2. Figure 7 shows the linearized $\ln k_{\mathrm{p} 1}$ versus reciprocal temperature plots for various initial sorbent concentration values. $E_{\mathrm{a}}$ values have been found to be $-11.42,-13.53,-33.45,-34.88$ and $-66.48 \mathrm{~kJ} \mathrm{~mol}^{-1}$ for initial metal concentrations of $2.5,5.0,7.5,10.0$ and $50.0 \mathrm{mg} \mathrm{L}^{-1}$, respectively. Negative nature of the activation energy values suggest that biosorption of $\mathrm{Co}(\mathrm{II})$ onto $S$. pombe is barrierless in these concentration ranges but no further physical interpretation is possible expect that the process is exothermic. This is an advantageous feature as it implies a low-cost operation with lower energy requirements, quick recovery and minimal loss of efficiency when compared to endothermic operations.

Further thermodynamic properties of the biosorption system were determined using equations 3 and 4 . The calculated values for $\Delta S^{\circ}$ and $\Delta \mathrm{H}^{\circ}$ are reported in Figure 8. The equilibrium constant from the Freundlich isotherm model was used for the thermodynamic calculations although statistically the Temkin isotherm was a better fit, albeit marginally. The reason for this is the thermodynamic consistency the calculations with the Freundlich equilibrium constants provide which is lacking in the Temkin calculation.

It can be observed from Figure 9 that increasing the operating temperature of the biosorption process has detrimental effects on two critical process metrics, namely the time required to reach equilibrium and metal uptake at equilibrium. Accordingly, it can be argued that, in terms of recovery of the metal from solution, temperature increase

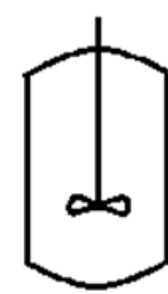

$\mathrm{V}=$ Operational volume (L)

$\mathrm{Ci}=$ Initial aqueous metal concentration $\left(\mathrm{mg} \mathrm{L}^{-1}\right)$

$\mathrm{Ce}=$ Aqueous metal concentration at equilibrium $\left(\mathrm{mg} \mathrm{L}^{-1}\right)$

qi $=$ Initial metal uptake $\left(\mathrm{mg} \mathrm{g}^{-1}\right)$

$\mathrm{qe}=$ Metal uptake at equilibrium $\left(\mathrm{mg} \mathrm{g}^{-1}\right)$

[Spombe] = Biosorbent mass (g) / Volume (L)

Figure 5: Batch biosorber

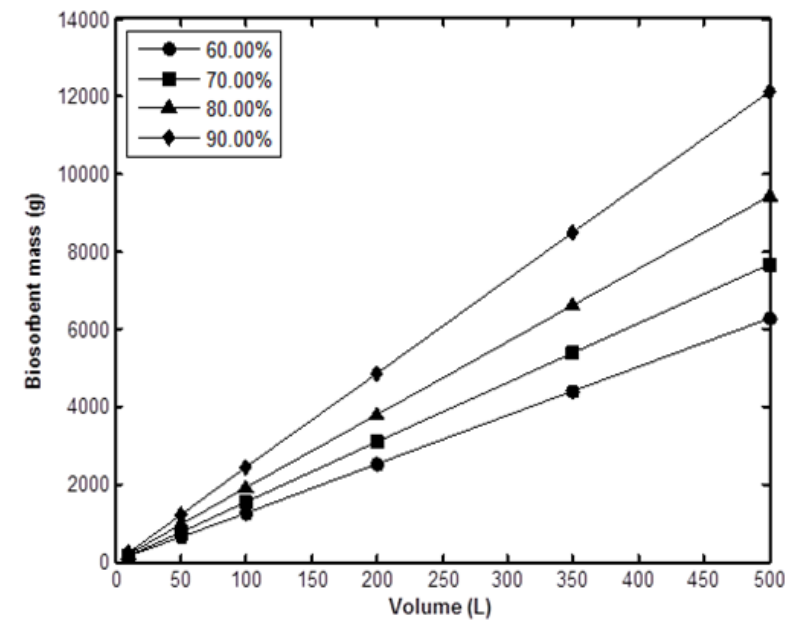

Figure 6: Biosorbent mass required for target percentage removal of metal at various operating volumes @ $250 \mathrm{c}$. makes this process less favourable. Thermodynamic interpretation of such a biosorption process with above-mentioned features suggests that the $\Delta G^{\circ}$ of the process should increase with increasing operating temperature. Thermodynamic properties calculated using the equilibrium constants acquired from the fitting of experimental data to biosorption isotherms produce trends that suggest otherwise with the exception of Freundlich and Redlich-Peterson models which exhibit acceptable thermodynamic consistency. Thermodynamically inconsistent predictions are expectable since these isotherm models are highly empirical and lack physical meaning; even though they offer statistically very accurate representation of equilibrium data $[10,13]$. Following these considerations, for the calculation of thermodynamic parameters, the equilibrium constant from the thermodynamically consistent isotherm model rather than the statistically most successful one will be used; as long as the former carries an acceptable correlation factor. Different trends depending on the isotherm model use can be observed in the calculated values of $\Delta G^{0}$ as reported in Table 5 .

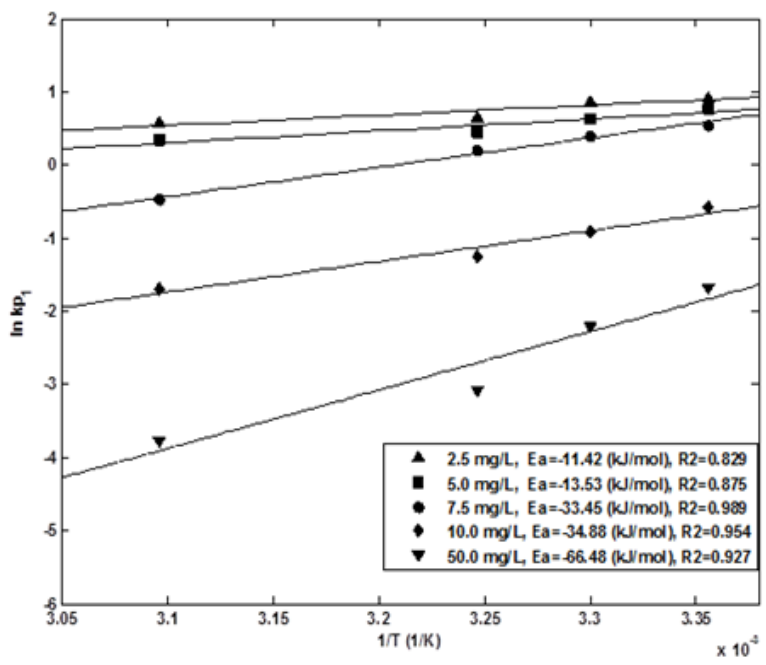

Figure 7: In $k_{p 1}$ versus $1 / T$ plots at different initial $\mathrm{Co}$ (II) concentrations.

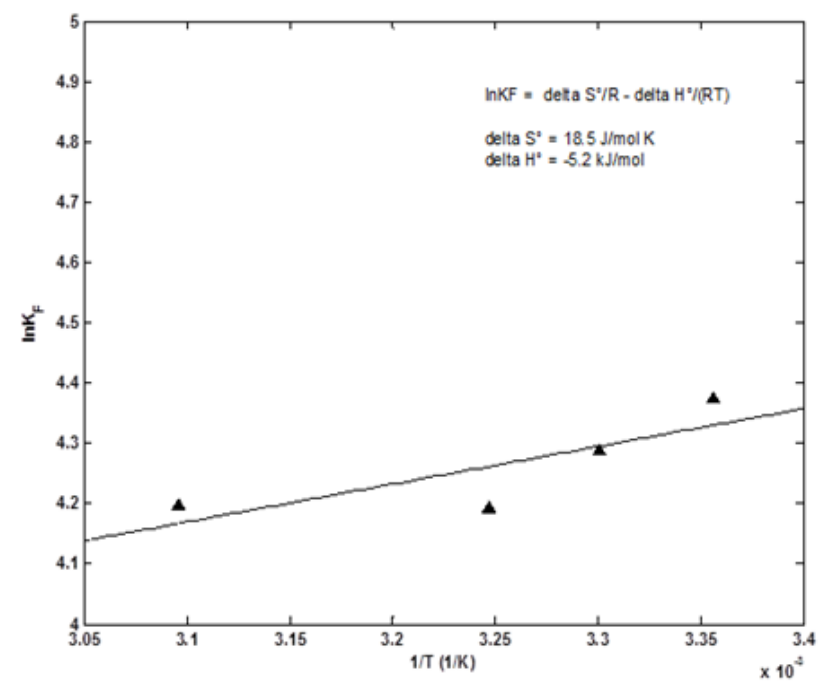

Figure 8: In $\mathrm{K}_{\mathrm{F}}$ versus 1/T plot 


\section{Conclusion}

Equilibrium, kinetic and thermodynamic analyses of a biosorption process are crucial for predicting its performance and comparison with alternatives. Among the various studied isotherm models, Temkin isotherm model has shown the best fit for the present data in terms of statistical success. The inclusion of a term for temperature in its mathematical structure and the experimentally observed fact that temperature has an inversely correlated effect on biosorption performance support this outcome. However, thermodynamic consistency with experimental observations in the calculation of thermodynamic properties of the system could only be achieved using equilibrium constants from the Freundlich isotherm model. This proves to be a situation where one has to choose the most appropriate model for the type of calculation needed. Indeed, equilibrium studies were conducted using the Temkin isotherm model whereas thermodynamic calculations were done incorporating the Freundlich equilibrium constant.

The $\Delta G^{0}$ values calculated for operating temperatures of $25,30,35$ and $50^{\circ} \mathrm{C}$ were $-11.7,-11.5,-11.3$ and $-11.3 \mathrm{~kJ} \mathrm{~mol}^{-1}$, respectively. The slight increase in the $\Delta G^{0}$ values with respect to increasing operating temperatures implies thermodynamic consistency with the observation from kinetic profiling simulations (Figure 9) that higher temperatures are less favourable for this particular system.

Among the isotherm models used only Temkin isotherm takes the natural logarithm of aqueous metal concentration whereas all the others incorporate this term either linearly or exponentially. Temkin isotherm seems to minimise the effect of aqueous metal concentration

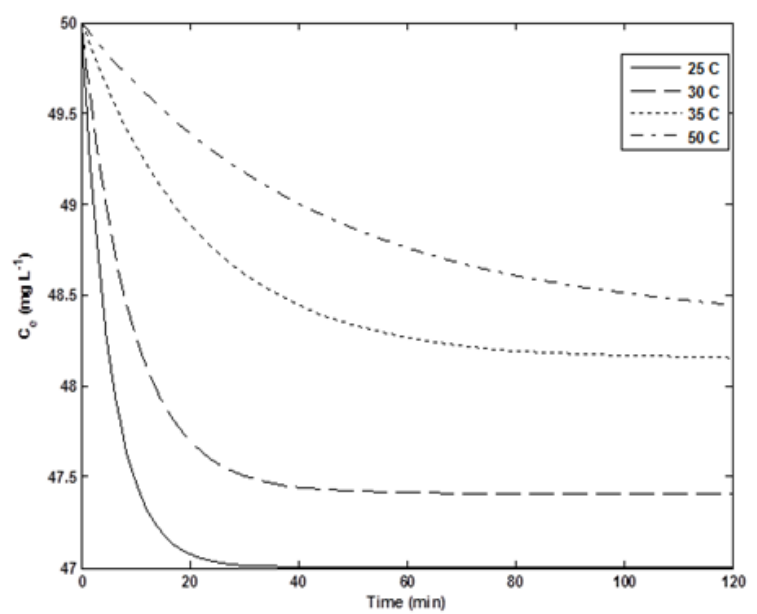

Figure 9: Kinetic profiling simulation of four biosorption processes taking place at different operating temperatures all with $\mathrm{C}=50 \mathrm{mg} \mathrm{L}^{-1}$ and biosorbent dose: $1 \mathrm{~g} \mathrm{~L}^{-1}$.

\begin{tabular}{|c|c|c|c|c|}
\hline & $\begin{array}{c}\Delta G^{0} @ 25^{\circ} \mathrm{C} \\
\left(\mathrm{kJ} \mathrm{mol}^{-1}\right)\end{array}$ & $\begin{array}{c}\Delta \mathrm{G}^{0} @ 30^{\circ} \mathrm{C} \\
\left(\mathrm{kJ} \mathrm{mol} \mathrm{mol}^{-1}\right)\end{array}$ & $\begin{array}{c}\Delta G^{0} @ 35^{\circ} \mathrm{C} \\
\left(\mathrm{kJ} \mathrm{mol}{ }^{-1}\right)\end{array}$ & $\begin{array}{c}\Delta G^{0} @ 50^{\circ} \mathrm{C} \\
\left.(\mathrm{kJ} \mathrm{mol})^{-1}\right)\end{array}$ \\
\hline Langmuir & -8.5 & -9.4 & -10.2 & -12.0 \\
\hline Freundlich & -11.7 & -11.5 & -11.3 & -11.3 \\
\hline Sips & -11.0 & -11.3 & -12.0 & -13.5 \\
\hline Khan & -16.3 & -14.2 & -14.9 & -13.6 \\
\hline Temkin & -35.0 & -37.8 & -41.5 & -52.4 \\
\hline Redlich-Peterson & -16.0 & -14.3 & -15.0 & -14.5 \\
\hline
\end{tabular}

Table 5: $\Delta G^{0}$ values calculated using equilibrium constants from different isotherm models. on equilibrium compared to all the other models. It has to be noted that this is in parallel with experimental observation. Although increased initial metal concentrations have a positive effect on the equilibrium values of $q_{\mathrm{e}}$ and $C_{\mathrm{e}}$, this is a marginal effect and insignificant with that of other factors such as temperature. The success of the Temkin isotherm model may be due to its reflecting this fact.

The above observation is supported by the outcome of the biosorption kinetics study as well. Pseudo-first order kinetics provides a statistically superior correlation of experimental data compared to the pseudo-second order kinetics. The mathematical difference between the two is the taking of the square of the concentration term in the pseudo-second order kinetics increasing its influence on the overall kinetic behaviour of the biosorption system. The fact that pseudo-first order kinetics better describes the observed values is in agreement with the earlier suggestion. The fact that this biosorption system follows pseudo-first order kinetics hints that a costly destructive desorption step might not be necessary in order to free the biosorbent for reuse.

It is important to integrate biosorbent characterisation information with preliminary process design calculations from an early point onwards. The use of isotherm models to simulate the single stage biosorber performance plots (Figure 6) and the subsequent identification of possible techno-economic trade-off points can be considered a tool for early stage process design.

Overall, the biosorption of Co(II) by wild-type $S$. pombe seems to be a slightly exothermic process, judging by the negative nature of the calculated $\mathrm{E}_{\mathrm{a}}$ values and thermodynamically feasible, considering that the calculated $\Delta G^{0}$ values are negative for all the conditions tested. However, this particular biosorption process is not a very efficient one since a maximum of about $50 \%$ percentage removal of metal is possible even under optimal conditions. This value is obtained when lower initial metal concentrations are used. For higher initial metal concentrations the percentage removal falls dramatically to under $20 \%$ for $10 \mathrm{mg} \mathrm{L}^{-1}$ initial Co(II) concentration and $~ 5 \%$ for $50 \mathrm{mg} \mathrm{L}^{-1}$ initial Co(II) operations. This means that while S. pombe is not an ideal biosorbent for the removal of $\mathrm{Co}$ (II) from aqueous solutions, it can be utilised as a bioseparation agent for aqueous mixtures containing both $\mathrm{Ni}(\mathrm{II})$ and $\mathrm{Co}(\mathrm{II})$ since its affinity towards $\mathrm{Ni}(\mathrm{II})$ is significantly higher (Durmaz-Sam et al., 2011).

Future work could focus on the characterisation of $S$. pombe in multi-component biosorption processes involving both $\mathrm{Co}(\mathrm{II})$ and $\mathrm{Ni}(\mathrm{II})$. Additionally, alternative design considerations for better utilisation of $S$. pombe, such as the use of column systems instead of a batch stirred tank reactor or the immobilisation of $S$. pombe could be studied. Inclusion of mass transfer and fluid-flow calculations would improve the preliminary design approaches. Finally, quantified techno-economic assessment of the design trade-offs using cost-benefit analyses would enhance the industrial feasibility studies.

\section{Acknowledgements}

Funding by Marmara University Scientific Research Committee (Project FENC-YLP-010710-0231) is gratefully acknowledged.

\section{References}

1. Wang J, Chen C (2009) Biosorbents for heavy metal removal and their future Biotechnol Adv 27: 195-226.

2. Durmaz-Sam S, Sayar NA, Topal-Sarikaya A, Sayar AA (2011) Biosorption of $\mathrm{Ni}(\mathrm{II})$ by Schizosaccharomyces pombe: kinetic and thermodynamic studies. Bioprocess Biosys Eng 35: 997-1005.

3. Kuyucak N, Volesky B (1989) Accumulation of cobalt by marine algae Biotechnol Bioeng 33: 809-814. 
Citation: Sayar NA, Durmaz-Sam S, Odabasi G, Sayar AA (2013) Biosorption of Co(II) by Schizosaccharomyces pombe: Kinetic and Thermodynamic Studies for Process Design. J Bioprocess Biotech 3: 138 doi: 10.4172/2155-9821.1000138

Page 8 of 8

4. Vijaraghavan K, Palanivelu K, Velan M (2006) Biosorption of copper(II) and cobalt(II) from aqueous solutions by crab shell particles. J Hazard Mater 97 $1411-1419$.

5. Pal A, Ghosh S, Paul A (2006) Biosorption of cobalt by fungi from serpentine soil of Andaman. Bioresource Technol 97: 1253-1258.

6. Li B, Liu F, Wang J, Ling C, Li L, et al. (2012) Efficient separation and high selectivity for nickel from cobalt-solution by a novel chelatin resin: batch, column and competition investigation. Chem Eng J 195-196: 31-39.

7. Kumbasar RA, Sahin I (2008) Separation and concentration of cobalt from ammoniacal solutions containing cobalt and nickel by emulsion liquid membranes using 5,6-dibromo-8-hydroxyquinoline (DBHQ). J Membrane Sci 325: 712-718.

8. Ozer A, Ozer D (2003) Comparative study of biosorption of $\mathrm{Pb}(\mathrm{II}), \mathrm{Ni}(\mathrm{II})$ and
$\mathrm{Cr}(\mathrm{IV})$ ions onto $\mathrm{S}$. ceravisiae: determination of biosorption heats. J Hazard Mater 100: 219-229.

9. Volesky B (2003) Bioprocess process simulation tools. Hydrometallurgy 71 179-190.

10. Liu Y, Liu YJ (2008) Biosorption isotherms, kinetics and thermodynamics. Sep Purif Technol 61: 229-242.

11. Foo KY, Hameed BK (2010) Insight into the modelling of adsorption isotherm systems. Chem Eng J 156: 2-10.

12. Hameed BH, Mahmoud DK, Ahmad AL (2008) Equilibrium modelling and kinetic studies on the adsorption of basic dye by a low-cost adsorbent: Coconut (Cocos nucifera) bunch waste. J Hazard Mater 158: 65-72.

13. Levan MD, Vermeulen T (1981) Binary Langmuir and Freundlich isotherms for ideal adsorbed solutions. J Phys Chem-Us 85: 3247-3250. 